\title{
Domestic Policies, Hidden Protection and the GATT/WTO
}

\author{
Claustre Bajona \\ University of Miami
}

\author{
Josh Ederington \\ University of Kentucky
}

December 2006

\begin{abstract}
As tariff barriers have fallen worldwide, regulation of domestic policy has become increasingly important in international trade agreements. This has led to the emergence of a theoretical literature addressing the integration of perfectly observable domestic policy into trade agreements. However, the assumption that domestic policy is perfectly observable is problematic since the interpretation and enforcement of domestic policy statues is often non-transparent. Thus, it may be difficult to determine whether lack of market access is due simply to random shocks or to the use of domestic policies as hidden trade barriers. In this paper, we model international coordination over trade and domestic policy when domestic policy is private information and thus can be used as a form of "hidden protection". We show that the optimal design of an efficient agreement depends greatly on whether domestic policy is observable or unobservable.
\end{abstract}

JEL Classification: F1, F13, K33, H2

KEYWORDS: trade policy, environmental standards, international agreements

\section{Introduction}

Under the auspices of the General Agreement on Tariffs and Trade (GATT), the international community has made great strides in lowering tariff barriers to trade. However, as tariff barriers have fallen, regulation of domestic policies, such as environmental regulations or labor standards, has become increasingly important in international trade agreements. This has led to 
the emergence of a theoretical literature addressing the integration of domestic policy into trade agreements. There are three key results in this literature. First, there is the "national sovereignty" argument of Bagwell and Staiger (2001) that an efficient international trade agreement covering multiple policy instruments only need specify a minimum level of foreign market access (the actual policy mix in achieving that level of access can be chosen unilaterally). Second, there is the "differential treatment" argument of Ederington (2001) that, given limited enforcement that precludes full cooperation, protection in the form of tariffs is preferable to protection via internal taxes and regulations. Finally, there is the "linkage" argument of Ederington (2002) and Limao (2005) that allowing cross-retaliation across policy instruments (e.g., threatening trade policy sanctions for deviations in domestic policy) is weakly optimal.

However, the above literature assumes that domestic policy is perfectly observed. We find this problematic. Most basically, even when domestic policy statutes are transparent, the actual use and enforcement of such statutes is decidedly less so. Thus, it may be difficult to determine whether lack of market access is due simply to random shocks or to the use of domestic policies as hidden trade barriers. In this paper, we model international coordination over trade and domestic policy when domestic policy is private information. We show that none of the results derived from perfect information models transfers fully to an imperfect-information setting.

First, the "national sovereignty" argument is based on the fact that the key inefficiency is not the policy mix, but an inefficiently low level of foreign market access when policies are set unilaterally. As we show in this paper, the results of Bagwell and Staiger (2001) extend naturally to the case of self-enforcing agreements (i.e., agreements where cooperation is maintained by the threat of future punishment if cheating occurs) provided that both trade policy and domestic policy are perfectly observable. However, this is no longer the case when domestic policy is unobservable (i.e., the foreign country cannot distinguish between hidden protection and random fluctuations in import volume). Rather, we show that in addition to specifying a minimum level of market access, a well-designed international agreement should also establish a binding tariff ceiling as a means of forcing countries wishing to deviate from the agreement to use hidden domestic policy as the deviating policy. Since domestic policy is a second-best instrument for restricting market access, the corresponding incentive to deviate from the agreement is less and greater cooperation can be maintained.

Second, the "differential treatment" argument is based on the fact that trade policy is the first-best means by which countries would choose to 
deviate from an agreement and thus, given limited enforcement power, tariff barriers are the most efficient means of affording countries protection so as to maintain the viability of the agreement. However, as we show in this paper, the results of Ederington (2001) no longer apply when imperfect information is unobservable. Intuitively, the "hidden protection" aspect of domestic policy makes it a more attractive means of deviating from the agreement and thus, an efficient international agreement will relax cooperation in domestic policy (as well as trade policy) to hold the incentive to deviate in domestic policy in check.

Finally, the "linkage" argument is based on the fact that, in models of perfect information, punishment is never triggered and thus maximal punishment is always optimal. Since allowing cross-retaliation increases the amount of punishment available to deter deviations, an efficient selfenforcing agreement will allow such cross-retaliation in order to maximize the amount of cooperation that can be maintained. However, when domestic policy is unobservable there is a positive probability that punishment will be triggered when no cheating has taken place (as a low level of market access could be a signal that the foreign country is deviating from the agreement, or it could be simply due to unobservable market fluctuations). Thus, the potential for mistaken punishment implies that limitations should be placed on the severity of punishment that occurs. As we show in this paper, there exists a set of conditions under which a non-linked agreement (which forbids cross-retaliation) is preferable to a linked agreement.

The structure of the paper is as follows. In Section 2 we construct a standard model of trade in which trade volume is subject to random productivity shocks and governments have access to both trade and domestic policy instruments. Our model follows the conventional literature in which international agreements exist to assist countries in escaping from a terms-of-trade driven prisoner's dilemna (see Bagwell and Staiger (1999)). In Section 3 we assume that both trade policy and domestic policy are perfectly observable, and derive a set of rules governing the efficient treatment of domestic policy within a self-enforcing international trade agreement. In Sections 4-6, we assume that domestic policy is unobservable (and thus enforcement of the agreement is maintained by trade volume triggers) and demonstrate that the appropriate treatment of domestic policy differs greatly from the case of perfect observability. Finally, in Section 7 we conclude. 


\section{The model}

In this section we construct a standard general equilibrium model of trade between two countries, a home country (no *) and a foreign country $(*)$. The government of each country has access to two policy instruments: a trade instrument (tariff on the imported good) and a domestic policy instrument (tax/subsidy to production in the importing sector). Each country has the ability to produce three goods: a homogeneous good, $j=0$, and two differentiated goods, $j=x, y$, all of which are traded. We assume that they produce the homogeneous good using identical technologies, but that the home country has an absolute advantage in producing good $y$ and the foreign country has an absolute advantage in producing good $x$. Under these assumptions, good $x$ is the import good of the home country and good $y$ is the import good of the foreign country. In what follows we describe in detail the model economy. We assume that countries are completely symmetric and omit the country's superscript when not needed. ${ }^{1}$

\subsection{Consumers}

Each country is populated by a measure 1 of identical, infinitely-lived consumers who discount the future at a rate $\delta$. Consumers derive utility from consumption of the three goods. We assume that preferences are quasi-linear in the homogeneous good and can be represented by the period utility function:

$$
u(c)=c_{0}+\left[c_{x}-\frac{c_{x}^{2}}{2}\right]+\left[c_{y}-\frac{c_{y}^{2}}{2}\right]
$$

where $c_{i}$ represents consumption of good $i$. Consumers are endowed with $l$ units of labor which they supply inelastically.

\section{$2.2 \quad$ Producers}

The homogeneous good technology transforms labor inputs into product at a rate of $1-1$. The production function can be written as,

$$
y_{0}=l_{0}
$$

\footnotetext{
${ }^{1}$ For simplicity, we assume that no international borrowing or lending is allowed and that there is no storage technology available. Under these assumptions consumers and producers face the same problem every period, as a function of government policies, and solve a static problem.
} 
Notice that under this production function, in equilibrium the economy's wage is equal to the price of the homogeneous good. In what follows we normalize the price of the homogeneous good to 1 and, thus, the equilibrium wage will also be equal to 1 .

Goods $x$ and $y$ are produced using labor and an industry-specific fixed factor. $^{2}$ Without loss of generality, we normalize the amount of the fixed factor in each industry to be 1 . We assume that the home country has an absolute advantage in producing good $y$ and the foreign country has an absolute advantage in producing good $x$. Specifically, the production function for the for the export good in each country is given by:

$$
y_{i}=\left[2 l_{i}\right]^{\frac{1}{2}}
$$

where $y_{i}$ represents production of good $i$. Likewise the production function for the import good in each country is given by:

$$
y_{i}=l_{i}^{\frac{1}{2}}+\phi
$$

Note that the importing sector of each country is affected by period productivity shocks. We assume that the shock, $\phi$, takes on the value 0 with probability $1-\alpha$ and the value $\theta$ with probability $\alpha$. We assume that the period value of $\phi$ is known to firms and consumers when making their period decisions and is fixed at a level to avoid reversals on the importing sector. $^{3}$

\subsection{Government}

The government's objective is to choose policy instruments in order to maximize consumers' expected lifetime welfare. The policy instruments that are available to the government are trade policy (a tariff on the imported differentiated good), $\tau$, and domestic policy (a subsidy on production of the imported differentiated good), $t$.

Every period, given government policies, consumers and firms choose their optimal behavior after productivity shocks are realized. In what follows, we denote as "competitive equilibrium" the solution of the consumers' and firms' problems as functions of the government policies.

\footnotetext{
${ }^{2}$ These assumptions on preferences and technology greatly simplify the model, since they make policies in one country independent of policies in the other country. In particular, under these assumptions the world price of each differentiated good is independent of the policies affecting the other differentiated good.

${ }^{3}$ Given equilibrium policies, this requires that $\theta<1 / 4$.
} 


\subsubsection{Competitive equilibrium}

In what follows all prices and, thus, the solution of the consumers' and firms problems are functions of government policies and technology shocks. In order to simplify notation we do not make these dependences explicit.

The consumers'objective is to maximize their expected lifetime utility. Given that there is no storage technology in the model, and international borrowing and lending is not allowed, consumers spend all their income in the period consumption goods and, therefore, they solve the following static problem every period:

$$
\begin{array}{ll}
\max & \left\{c_{0}+\left[c_{x}-\frac{c_{x}^{2}}{2}\right]+\left[c_{y}-\frac{c_{y}^{2}}{2}\right]\right\} \\
\text { st } & c_{0}+q_{x} c_{x}+q_{y} c_{y}=m \\
& c_{0} \geq 0
\end{array}
$$

where $q_{j}$ represents the consumer's price of good $j$ and $m$ is the consumer's income. In this formulation of the problem we have normalized the price of the homogeneous good to 1 .

From the first order conditions, assuming that the parameters are such that consumers consume the homogeneous good in equilibrium, we derive the expression for the demand of each good as functions of prices and income, $m$ :

$$
\begin{aligned}
& c_{x}=1-q_{x} \\
& c_{y}=1-q_{y} \\
& c_{0}=m-\left(1-q_{x}\right) q_{x}-\left(1-q_{y}\right) q_{y}
\end{aligned}
$$

Firms in the differentiated sectors $j=1,2$ maximize period profits subject to the technology constraint:

$$
\begin{aligned}
\max & \left\{p_{j} y_{j}-w l_{j}\right\} \\
& y_{j}=f\left(l_{j}\right)
\end{aligned}
$$

where $p_{j}$ denotes the producer's price of the good and $f\left(l_{j}\right)$ denotes the production function of the good.

Profit maximization in the numeraire sector sets the wage rate in the economy at one. From the first order conditions of the above problem, we derive labor demanded, output and profits for the home country as functions of prices (expressions for the foreign country are symmetrically defined):

$$
\begin{aligned}
& l_{x}=\left(\frac{p_{x}}{2}\right)^{2} \text { and } l_{y}=\frac{p_{y}{ }^{2}}{2} \\
& y_{x}=\frac{p_{x}}{2}+\phi \text { and } y_{y}=p_{y} \\
& \pi_{x t}=\frac{p_{x}^{2}}{4}+p_{x} \phi \text { and } \pi_{y}=\frac{p_{y}^{2}}{2}
\end{aligned}
$$


where $\pi_{j}$ are the profits of industry $j=1,2$.

We assume that consumers own the firms in the economy. The government redistributes revenue from taxation and tariffs back to the consumers. Therefore, we can write the consumer's income as:

$$
m^{i}=w^{i} l^{i}+\sum_{j} \pi_{j}^{i}+\tau^{i} M_{i}^{i}-t^{i} y_{i}^{i}
$$

where $M_{i}^{i}$ represents net imports of good $i$.

Definition 1 A competitive equilibrium of the static problem of this economy is a sequence of functions of the government policies $\tau^{i}, t^{i}$ and technology shocks $(\phi)$ : consumer and producer decisions, $\left\{c_{j}^{i}, y_{j}^{i}, l_{j}^{i}\right\}_{i j}$ and prices $\left\{q_{j}^{i}, p_{j}^{i}, p_{j}^{w}, w^{i}\right\}$ such that:

(i) given prices and income as defined in (9), $\left\{c_{j}^{i}\right\}_{i j}$ solve the consumers problem

(ii) given prices, $\left\{y_{j}^{i}, l_{j}^{i}\right\}_{i j}$ solve the producers problems

(iii) goods and labor markets clear, that is:

$$
\begin{gathered}
c_{j}+c_{j}^{*}=y_{j}+y_{j}^{*} \quad j=0,1,2 \\
l_{0}^{i}+l_{1}^{i}+l_{2}^{i}=l^{i} \quad i=\text { home, foreign }
\end{gathered}
$$

(iv) consumer and producer prices are defined as:

$$
\begin{aligned}
& q_{i}^{i}=p_{i}^{w}+\tau^{i} \\
& q_{-i}^{i}=p_{-i}^{w} \\
& p_{i}^{i}=p_{i}^{w}+\tau^{i}+t^{i} \\
& p_{-i}^{i}=p_{-i}^{w}
\end{aligned}
$$

where good $i$ is the importing good and good $-i$ is the exporting good for country $i$.

Notice that, since consumers face the same static problem every period, a competitive equilibrium for the economy is just a sequence of static competitive equilibria. From the market clearing conditions, one can solve for world prices of each good as a function of government policy and the productivity shock:

$$
p_{x}^{w}=\frac{1}{7}[4-3 \tau-t-2 \phi] \text { and } p_{y}^{w}=\frac{1}{7}\left[4-3 \tau^{*}-t^{*}-2 \phi\right]
$$


Given these world prices, we can also determine import volume for each country:

$$
M_{x}=\frac{1}{7}[1-6 \tau-2 t-4 \phi] \text { and } M_{y}^{*}=\frac{1}{7}\left[1-6 \tau^{*}-2 t^{*}-4 \phi\right]
$$

\subsubsection{Government objectives}

Finally, we assume that governments maximize national welfare (the aggregate utility of the representative consumers within the country). Let us define $W^{i}\left(\tau, t, \tau^{*}, t^{*}\right)$ as the expected welfare in country $i$ when governments' policies are $\left(\tau, t, \tau^{*}, t^{*}\right)$. Welfare for the home country can be split into two components, where welfare from the import good and export good respectively are given by:

$$
\begin{gathered}
W_{x}(t, \tau) \equiv \int_{\hat{p}_{x}^{d}}^{1} c_{x}(t, \tau) d \hat{p}+\pi_{x}(t, \tau)+\tau \cdot M_{x}(t, \tau)-t \cdot y_{x}(t, \tau) \\
W_{y}\left(t^{*}, \tau^{*}\right) \equiv \int_{\hat{p}_{y}^{d}}^{1} c_{y}\left(t^{*}, \tau^{*}\right) d \hat{p}+\pi_{y}\left(t^{*}, \tau^{*}\right)
\end{gathered}
$$

Aggregate welfare is then given by: $W\left(t, \tau, t^{*}, \tau^{*}\right)=W_{x}(t, \tau)+W_{y}\left(t^{*}, \tau^{*}\right)$. Foreign welfare is defined symmetrically as the sum of welfare from its import and export goods (that is $\left.W^{*}\left(t, \tau, t^{*}, \tau^{*}\right)\right)=W_{x}^{*}(t, \tau)+W_{y}^{*}\left(t^{*}, \tau^{*}\right)$.

\section{Self-Enforcing Agreements in the Absence of Un- certainty}

In this section, we will consider the case where both trade and domestic policy are perfectly observable and the productivity shock is observed by both governments before they make their policy choices. Thus, we consider a situation of complete certainty. In the absence of an international agreement, each country sets trade taxes and production taxes to maximize national welfare, taking the policy choices of its trading partner as given. Taking the derivatives of $W\left(t, \tau, t^{*}, \tau^{*}\right)$ with respect to $t$ and $\tau$, and solving out the first order conditions, the unilaterally optimal trade and domestic policies for the home country $\left(t^{D}, \tau^{D}\right)$ are given by: ${ }^{4}$

\footnotetext{
${ }^{4}$ Best-response functions for the foreign country are defined symmetrically. Since markets for the two goods are independent and export policies are prohibited, these optimal policy choices are independent of foreign policy. The assumptions made about the func-
} 


$$
\tau^{D}(t)=\frac{1}{20}(1-4 \phi)-\frac{1}{3} t \text { and } t^{D}(\tau)=\frac{20}{23}\left[\frac{1}{20}(1-4 \phi)-\tau\right]
$$

Note from (16) that free-trade is not unilaterally optimal for the home country. Within this model, both countries are large and can influence the terms-of-trade with either their trade or domestic policies. Thus, there exists a unilateral incentive for each country to erect barriers to trade (with either tariffs or domestic taxes) as a means of pursuing terms-of-trade gains. From (16) one derives that the Nash equilibrium trade and domestic policies for each country will be defined by:

$$
t^{N}=0, \quad \tau^{N}=\frac{1}{20}(1-4 \phi)
$$

Note from (17) that each country is imposing a positive import tariff in order to restrict trade while setting non-distortionary domestic taxes. This is the standard result of welfare analysis: in the presence of an international trade distortion (the terms-of-trade distortion), trade policy is the first-best policy choice.

The previous section established that countries have a unilateral incentive to erect trade barriers. However, while imposing barriers to trade may be unilaterally optimal, it is not optimal from a worldwide standpoint. Globally efficient trade and domestic policies will be set to maximize joint welfare $\left(W+W^{*}\right)$, and will serve as the natural goals toward which countries strive when they cooperate. In this paper, we focus on symmetric international agreements in which countries set common cooperative trade policies $\left(\tau=\tau^{*}=\tau^{c}\right)$ and domestic policies $\left(t=t^{*}=t^{c}\right)$, since common policies within the symmetric model imply that both countries share equally in the gains to cooperation.

Given that countries set common cooperative policies, the symmetry of the model implies that maximization of joint welfare will be equivalent to maximization of a single country's welfare. Define $W^{c}\left(t^{c}, \tau^{c}\right)$ as the cooperative level of welfare (i.e., $W\left(\tau=\tau^{*}=\tau^{c}, t=t^{*}=t^{c}\right)=W^{c}\left(t^{c}, \tau^{c}\right)$ ). Taking derivatives of $W^{c}\left(t^{c}, \tau^{c}\right)$ with respect to $t^{c}$ and $\tau^{c}$ one finds that globally efficient trade $\left(\bar{\tau}^{c}\right)$ and domestic $\left(\bar{t}^{c}\right)$ policies are given by free trade $\left(\bar{\tau}^{c}=0\right)$ and the non-distortionary domestic taxes $\left(\bar{t}^{c}=0\right)$. Intuitively,

tional forms of the model also ensure that the second-order conditions are satisfied and that a unique Nash equilibrium (in which the first-order conditions of (16) and the equivalent conditions for the foreign country hold simultaneously with positive trade volume) exists. 
there is no reason for policy intervention driven by beggar-thy-neighbor, trade-restricting motivations in an efficient cooperative arrangement. Thus, the goal of international cooperation is to achieve efficiency by (i) eliminating the terms-of-trade motivations from each country's trade policy decisions and (ii) preventing each country from distorting its domestic policy as a secondary means of protection.

\subsection{Self-enforcing Agreements}

Unfortunately, the desire to erect trade barriers does not disappear once an agreement is in place, and a critical problem faced by any international agreement is the lack of an external enforcement mechanism to ensure that the signatories to an agreement uphold their obligations. In the absence of direct enforcement, an agreement will only be viable if it is self-enforcing (i.e., member countries must view their continued cooperation to be in their own best interest). Bagwell and Staiger (1990) and Dixit (1987) argue that countries can support lower trade barriers in a repeated game setting by threatening to retaliate against countries that deviate from the agreement. Thus, in these models, the threat of retaliation assists in maintaining lower trade barriers.

In this section, an agreement is assumed to specify common, cooperative policies $\left(\tau=\tau^{*}=\tau^{c}\right.$ and $\left.t=t^{*}=t^{c}\right)$ and any defection from these cooperative policies is punished by reversion to a punishment path. Specifically, if each country were to set $\tau^{c}$ as their trade policy and $t^{c}$ as their domestic policy, then punishment would never be triggered and:

$$
V\left(\tau^{c}, t^{c}\right) \equiv \frac{1}{1-\delta} W\left(\tau=\tau^{*}=\tau^{c}, t=t^{*}=t^{c}\right)
$$

where $V$ denotes the discounted value of cooperating with the agreement and $\delta \in(0,1)$ represents the discount factor (the weight placed on future welfare).

In this paper, we consider the case where deviations from cooperative policies trigger infinite reversion to Nash equilibria (similar results can be obtained if one considers the case where punishment occurs for only a fixed finite length of time). In a linked agreement, where cross-retaliation is permitted, any observed deviation, in either trade or domestic policy, triggers infinite reversion to the full Nash equilibrium. Thus, if a country chooses to deviate from a linked agreement, it will deviate, in both policy instruments, to unilaterally optimal policies defined by (17). Defining $W^{N} \equiv W\left(\tau=\tau^{*}=\tau^{N}, t=t^{*}=t^{N}\right)$ as the Nash level of welfare, the 
discounted value of deviating from the agreement, $D_{\tau, t}$, is given by:

$$
D_{\tau, t} \equiv W\left(\tau=\tau^{N}, t=t^{N}, \tau^{*}=\tau^{c}, t^{*}=t^{c}\right)+\frac{\delta}{1-\delta} W^{N}
$$

For an agreement to be viable, it must be the case that neither country has an incentive to deviate from the agreement in either policy. Thus, an international agreement results in both countries jointly choosing trade and domestic policies to maximize the cooperative level of welfare, subject to a set of self-enforcement constraints (which entail balancing the gain to remaining in the agreement versus the gain to deviation). This implies that, within a linked agreement, countries maximize $V$ subject to:

$$
V \geq D_{\tau, t}
$$

The solution to the above maximization is a set of policies $\hat{\tau}^{c}, \hat{t}^{c}$ that we refer to as "most-cooperative policies". In the following sections, we establish several well-known results about the structure of optimal agreements given perfect information.

\subsection{Differential Treatment}

The first basic result is the "differential treatment" result of Ederington (2001) which argues that, when limited enforcement power prevents countries from implementing the globally efficient set of trade and domestic policies, countries should cooperate fully over domestic policy and only relax cooperation in trade policy to satisfy the self-enforcement constraint. This result is established in the following Lemma:

LEMMA 1 Within a self-enforcing international agreement with perfectly observable domestic policy, the most-cooperative domestic policy is nondistortionary (i.e., $\hat{t}^{c}=0$ ).

Proof:

Taking the Lagrangian of the above maximization with respect to $t^{c}$ and $\tau^{c}$ one derives the following first-order conditions for both the linked and nonlinked agreements:

$$
\begin{aligned}
& \frac{\partial V}{\partial t}-\lambda\left[\frac{\partial V}{\partial t}-\frac{\partial D_{\tau, t}}{\partial t}\right]=0 \\
& \frac{\partial V}{\partial \tau}-\lambda\left[\frac{\partial V}{\partial \tau}-\frac{\partial D_{\tau, t}}{\partial \tau}\right]=0
\end{aligned}
$$

It is direct to calculate, from the definitions of $V$ and $D_{t, \tau}$ that:

$$
\begin{aligned}
& \frac{\partial V}{\partial t^{c}}=\frac{1}{1-\delta} \frac{\partial W^{c}}{\partial t^{c}} \quad \text { and } \frac{\partial V}{\partial \tau^{c}}=\frac{1}{1-\delta} \frac{\partial W^{c}}{\partial \tau^{c}} \\
& \frac{\partial D_{\tau, t}}{\partial t^{c}}=\frac{\partial W_{\tau, t}^{D}}{\partial t^{c}} \quad \text { and } \quad \frac{\partial D_{\tau, t}}{\partial \tau^{c}}=\frac{\partial W_{\tau, t}^{D}}{\partial \tau^{c}}
\end{aligned}
$$


Substituting (22) into (21) and solving out for the Lagrange multiplier, one derives the condition for an interior maximization of welfare in either cooperative agreement:

$$
\frac{\partial W^{c} / \partial \tau^{c}}{\partial W^{c} / \partial t^{c}}=\frac{\partial W_{\tau, t}^{D} / \partial \tau^{c}}{\partial W_{\tau, t}^{D} / \partial t^{c}}
$$

Taking derivatives of the cooperative and deviating levels of welfare with respect to cooperative trade and domestic policies, one derives that:

$$
\begin{gathered}
\frac{\partial W^{C} / \partial \tau^{c}}{\partial W^{C} / \partial t^{c}}=\frac{-2 t^{c}-6 \tau^{c}}{-3 t^{c}-2 \tau^{c}} \\
\frac{\partial W_{\tau, t}^{D} / \partial \tau^{c}}{\partial W_{\tau, t}^{D} / \partial t^{c}}=\frac{-3+6 t^{c}+12 \phi+18 \tau^{c}}{-1+2 t^{c}+4 \phi+6 \tau^{c}}
\end{gathered}
$$

By (25) and (24), (23) is satisfied if $t^{c}=0$, and thus the most-cooperative domestic policy is non-distortionary. Q.E.D.

The intuition behind this result rests on first-best principles. The underlying reason countries want to defect from the international trade agreement is trade related (note that the international externality within the model is the terms-of-trade externality). Thus, allowing countries protection in trade policy, the most efficient means of affecting trade, will be the most efficient means of countering the incentive to deviate. Therefore, a cooperative agreement will result in setting domestic policy optimally (i.e., $\hat{t}^{c}=0$ ) and lowering tariff barriers as far as the self-enforcement constraint allows.

\subsection{National Sovereignty}

The second basic result is the "national sovereignty" result of Bagwell and Staiger (2001) which argues that an efficient agreement does not need to specify a set of cooperative policies (i.e., $\tau^{c}, t^{c}$ ). Rather, full cooperation can be achieved simply by setting a minimum level of market access (i.e., $\hat{M})$. It should be noted that Bagwell and Staiger (2001) consider the case where an international agreement can be externally enforced and thus enforcement constraints do not bind. Thus, before we consider the observability of domestic policy, we must extend the "national sovereignty" result to the context of a self-enforcing agreement in which cooperation is sustained by the threat of future retaliation. An obvious analogue is to consider the case where, rather than triggering punishment on deviating from a set of 
cooperative policies $\left(\tau \neq \tau^{c}\right.$ or $\left.t \neq t^{c}\right)$, punishment is triggered when market access falls below some minimum threshold (i.e., $M(\tau, t)<\hat{M})$. As we show in the following Lemma, consistent with Bagwell and Staiger (2001), an import volume trigger can support the same degree of cooperation as a conventional agreement which specifies cooperative policies:

LEMMA 2 Within a self-enforcing international agreement with perfectly observable domestic policy, the most-cooperative equilibrium can be obtained by an agreement that simply establishes a minimum level of market access (i.e., an import volume level) that each country must maintain.

Proof:

Define $\hat{M}\left(\hat{\tau^{c}}, \hat{t^{c}}, \phi\right)$ as the most-cooperative import volume level (where $\hat{\tau^{c}}$ and $\hat{t^{c}}$ are the most-cooperative polices solved for in the previous subsection). Let each country choose it's trade and domestic policy unilaterally, subject to a minimum level of market access defined by $\hat{M}$. Assume that this level of market access is enforced by the threat of infinite reversion to the Nash equilibrium (i.e., setting $M_{x}(t, \tau, \phi)<\hat{M}$ will trigger punishment). Note that, since most-cooperative policies are self-enforcing, $\hat{M}$ is self-enforcing as well. In this case, an agreement which sets $\hat{M}$ will result in the the home country choosing $t$ and $\tau$ to maximize $W\left(t, \tau, t^{*}, \tau^{*}\right)$ subject to $\left.M_{x}(t, \tau, \phi) \geq \hat{M}\left(\hat{\tau^{c}}, \hat{t^{c}}, \phi\right)\right)$. From the first-order conditions of this constrained maximization, one derives that:

$$
\frac{\partial W\left(\tau, t, \tau^{*}, t^{*}\right) / \partial \tau}{\partial W\left(\tau, t, \tau^{*}, t^{*}\right) / \partial t}=\frac{\partial M_{x}(\tau, t) / \partial \tau}{\partial M_{x}(\tau, t) / \partial t}
$$

Taking the above derivatives, one derives that (26) reduces to:

$$
\frac{6}{2}=\frac{3-20 t^{c}-12 \phi-60 \tau^{c}}{1-23 t^{c}-4 \phi-20 \tau^{c}}
$$

First, note that (27) is satisfied by setting non-distortionary domestic policy (i.e., $t=\hat{t}^{c}=0$ ). Second, note that, since the most-cooperative import volume is greater than the unilaterally optimal import volume, the country will raise its tariff until the import volume constraint binds (i.e., $\left.M_{x}(t, \tau, \phi)=\hat{M}\left(\hat{\tau^{c}}, \hat{t^{c}}, \phi\right)\right)$. Since $t=\hat{t}^{c}=0$, this implies that $\tau=\hat{\tau}^{c}$. Q.E.D.

It should be noted that the above lemma is a slightly restated version of the result of Bagwell and Staiger (2001). The results in that paper were referring specifically to globally efficient policies (unconstrained by limited 
enforcement power). In contrast, this paper is considering self-enforcing agreements. However, as can be seen from the above lemma, the results of Bagwell and Staiger (2001) naturally extend to the case of self-enforcing agreements. Second, note that the import volume trigger specified by an efficient agreement, $\hat{M}\left(\hat{\tau}^{c}, \hat{t^{c}}, \phi\right)$ is a function of the import volume shock, $\phi$. Thus, the minimum level of market access specified by the agreement will vary from period to period in line with any random shocks to productivity.

\subsection{Linkage}

The final basic result is the "linkage" result of Ederington (2002) and Limao (2005) that allowing cross-retaliation across policy instruments (e.g., threatening trade policy retaliation for deviations in domestic policy) is weakly optimal. The basic difference between the linked and non-linked agreements is that the linked agreement is configured so that cheating on any part of the agreement triggers retaliation in all parts of the agreement, while the non-linked agreement confines the retaliation to that part of the agreement where the cheating took place. Specifically, in both the linked and non-linked agreements, deviation in both trade and domestic policy will trigger reversion to the Nash equilibrium in both policies (i.e., the present discounted gain to deviating in both policies from the linked agreement $\left(D_{\tau, t}^{L}\right)$ and the non-linked agreement $\left(D_{\tau, t}^{N L}\right)$ is given by (19)). Thus, the self-enforcement constraint with respect to a deviation in both policies (i.e., $V \geq D_{\tau, t}$ ) is identical for the two types of agreement. However, in contrast to the linked agreement, deviation in a single policy from the cooperative equilibrium of a non-linked agreement triggers reversion to the Nash equilibrium in only that policy. Define $W_{\tau}^{D} \equiv W\left(\tau=\tau^{D}\left(t^{c}\right), t=t^{c}, \tau^{*}=\tau^{c}, t^{*}=t^{c}\right)$ as the period welfare for deviating from the agreement in trade policy, and $W_{\tau}^{N} \equiv W\left(\tau=\tau^{D}\left(t^{c}\right), t=t^{c}, \tau^{*}=\tau^{D *}\left(t^{c}\right), t^{*}=t^{c}\right)$ as the period welfare from a reversion to the Nash equilibrium in trade policy. In that case, the present discounted value of deviating from the agreement in trade policy alone is given by:

$$
D_{\tau}^{L}=W_{\tau}^{D}+\frac{\delta}{1-\delta} W^{N} \text { and } D_{\tau}^{N L}=W_{\tau}^{D}+\frac{\delta}{1-\delta} W_{\tau}^{N}
$$

Likewise, defining $W_{t}^{D} \equiv W\left(\tau=\tau^{c}, t=t^{D}\left(\tau^{c}\right), \tau^{*}=\tau^{c}, t^{*}=t^{c}\right)$, and $W_{t}^{N} \equiv W\left(\tau=\tau^{c}, t=t^{D}\left(\tau^{c}\right), \tau^{*}=\tau^{c}, t^{*}=t^{D *}\left(\tau^{c}\right)\right)$, the present discounted value of deviating from the agreement in domestic policy alone is given by:

$$
D_{t}^{L}=W_{t}^{D}+\frac{\delta}{1-\delta} W^{N} \text { and } D_{t}^{N L}=W_{t}^{D}+\frac{\delta}{1-\delta} W_{t}^{N}
$$


Within both a linked and non-linked agreement, countries choose $\tau^{c}$ and $t^{c}$ to maximize $V$ subject to the self-enforcement constraints that:

$$
V \geq D_{\tau, t}, V \geq D_{\tau}, V \geq D_{t}
$$

It should be apparent from the above discussion that the linked agreement threatens a tougher retaliatory episode for when a country deviates in only a single policy. As we show in the following Lemma, this implies that the linked agreement is weakly optimal:

LEMMA 3 Within a self-enforcing international agreement with perfectly observable domestic policy, allowing cross-retaliation across policy instruments is weakly optimal (i.e., a linked agreement is weakly preferred to a non-linked agreement).

Proof:

The fact that linkage is weakly optimal simply follows from the fact that punishment through reversion to the Nash equilibrium in both policies is greater than punishment in a single policy instrument $\left(W_{t}^{N} \geq W^{N}\right.$ and $W_{\tau}^{N} \geq W^{N}$ ). Given perfect information (i.e., the punishment phase is never triggered in equilibrium) such stronger punishment is always weakly preferred (see Abreu (1988)). Q.E.D.

A key question in the literature on self-enforcing trade agreements covering multiple policy instruments is whether such an agreement should be configured so that cheating on any part of it would trigger a costly retaliatory episode covering all parts of the agreement, or should retaliation be confined to the provisions where the cheating took place. For example, should one enforce obligations with respect to domestic policy (e.g., environmental or labor standards) within an international agreement with the threat of the suspension of trade concessions. A recent literature (e.g., Ederington (2002), Limao (2005)) has emerged that attempts to provide theoretical insight into this question. ${ }^{5}$ However, this literature has uniformly focused on models of complete information, where punishing any deviation with the strongest possible sanctions is optimal. Thus, it is not surprising that all of these papers conclude, as we have shown in the above proof, that linkage is weakly optimal. Indeed, the basic question analyzed by these papers is not the optimality of linkage, but rather the conditions under which it is strictly preferable to non-linkage. With respect to that case it is instructive to consider whether, under the conditions of the model introduced in this paper,

\footnotetext{
${ }^{5}$ Also see Spagnolo (1996) on the potential benefits of linkage over multiple policy issues.
} 
linkage is in fact necessary. Indeed, as a caveat to the above lemma, Ederington (2002) goes on to show that the non-linked agreement can support the same degree of cooperation as the linked agreement (i.e., the linked and non-linked agreements are functionally equivalent):

LEMMA 4 Within a self-enforcing agreement with perfectly observable domestic policy, linked and non-linked agreements can support the same degree of cooperation (i.e., $\hat{\tau}^{c}, \hat{t}^{c}$ ) provided there are no cross-border (nonpecuniary) externalities.

Proof:

Following Lemma 1 we evaluate the self-enforcement constraints at the point where $\hat{t}^{c}=0$. The self-enforcement constraint with respect to a deviation in both policies (i.e., $V \geq D_{\tau, t}$ ) is identical for the two types of agreement, and the lowest cooperative tariff that satisfies this constraint (i.e., $\hat{\tau}^{c}$ ) is given by:

$$
\hat{\tau}_{L}^{c}=\frac{(1-4 \theta)(17 \delta-10)}{60 \delta-200}
$$

Thus, if $\delta \geq 10 / 17$, than globally efficient policies $\left(\hat{t}^{c}=0, \hat{\tau}^{c}=0\right.$ are selfenforcing. If $\delta<10 / 17$ than $\hat{\tau}^{c}$ is given by (31). However, the non-linked agreement faces two additional constraints that $V \geq D_{\tau}^{N L}$ and $V \geq D_{t}^{N L}$. Given $\hat{t}^{c}=0$, it is direct to derive that the first additional constraint results in a $\hat{\tau}^{c}$ also given by (31) while the second constraint results in a $\hat{\tau}^{c}$ given by:

$$
\hat{\tau}_{N L}^{c}=\frac{(1-4 \theta)(44 \delta-23)}{236 \delta-460}
$$

It is direct to derive, from (31) and (32) that $\hat{\tau}_{L}^{c}>\hat{\tau}_{N L}^{c}$. Thus, at any $\hat{t}^{c}=0, \hat{\tau}^{c}$ such that $V=D_{\tau, t}$ the self-enforcement constraint with respect to a deviation in domestic policy alone does not bind. Since the only binding self-enforcement constraint is identical for both the linked and non-linked agreements, both agreements result in the same level of cooperation. Q.E.D.

\section{Self-Enforcing Agreements with Uncertainty}

In the above section, we considered optimal cooperation over trade and domestic policies given a situation of perfect information and full certainty. However, it seems natural to relax the assumption of perfect information, 
especially with respect to domestic policies and other non-tariff trade barriers. Indeed, almost all of the previous literature on negotiations over tariff and non-tariff trade barriers (e.g., Copeland (1990), Riezman (1991) and Hungerford (1991)) have assumed that non-tariff barriers were unobservable. As these papers stress, non-tariff trade barriers (especially domestic policies like labor and environmental standards) are not as transparent as tariffs, and thus are both more likely to be used by deviating countries (as hidden protection) and are more likely to be the cause of disagreements and trade wars across countries.

In this section, we adopt the view that domestic policies are less transparent and hence harder to monitor than trade policies. To formalize this view, we assume that countries cannot observe either the domestic policies of other countries or the realization of the random variable $\phi .{ }^{6}$ In contrast, the trade policy decisions of each country remain perfectly observable. In addition, uncertainty is introduced into the model by assuming that the productivity shock is only realized after governments make their policy decisions. Given this random uncertainty, there is an implicit expectations operator with respect to the following welfare calculations.

\subsection{Imperfect Information and Trigger Strategies}

Since trade policy remains observable, punishment can be triggered by any observed deviation from a cooperative level of trade policy, $\tau^{c}$. However, the unobservability of domestic policy raises the question of how cooperation can be maintained within an agreement if deviation from cooperative policies cannot be observed. For maintaining cooperation in domestic policy, we follow Green and Porter (1984) by using trigger strategies where strategies are conditioned on observables and, as in Riezman (1991), use import volume as our trigger. ${ }^{7}$ Thus, if import volume falls below some predetermined critical level $(\bar{M})$, countries will take that as evidence that cheating on the agreement has occurred and trigger the punishment phase. However, uncertainty within the model means that countries cannot always distinguish between hidden protection and random fluctuations in import volume. In

\footnotetext{
${ }^{6} \mathrm{~A}$ key difference between our model and that of Riezman (1991) is that he assumed that the unobservable domestic policies are perfect substitutes for a tariff. In our framework, unobservable domestic policy is an imperfect substitute for the tariff. This can be justified by assuming that disguising protection from foreign observation places constraints on the abilities of governments to replicate the efficiency of tariffs as a form of protection.

${ }^{7}$ As noted by Riezman (1991), this trigger strategy has the advantage of being both simple and corresponding to actual and proposed policy measures (e.g., the Trade Liberalization Priorities provision - Super 301 and the Gephardt Bill).
} 
the following sections, we analyze the respective costs and benefits to linking issues in the presence of this uncertainty.

We assume a self-enforcing agreement specifies both symmetric "cooperative" policies to be played in each period $\left(\tau^{c}\right.$ and $\left.t^{c}\right)$ and a import volume $(\bar{M})$ that triggers punishment. Note that, it contrast to the case of perfect information and certainty, our import volume trigger can not be made conditional on the unobservable random shock. Thus, if the home country sets policy such that if $M_{x}(\tau, t, \phi=\theta)>\bar{M}$ than punishment is never triggered by the home country. In contrast, if policy is set so that $M_{x}(\tau, t, \phi=0)<\bar{M}$ then punishment is triggered with probability one. Finally, if $M(\tau, t, \phi=0) \geq \bar{M}>M(\tau, t, \phi=\theta)$ than punishment is triggered with probability $\alpha$. As we show in the following Lemma, there are only three possible symmetric equilibria:

LEMMA 5 Given an import volume trigger, $\bar{M}$, there are only three possible symmetric equilibrium for a self-enforcing $t^{c}$ :

- (1) $t^{c}=t^{D}$

- (2) $t^{c}$ s.t. $M\left(\tau^{c}, t^{c}, \phi=\theta\right)=\bar{M}$

- (3) $t^{c}$ s.t. $M\left(\tau^{c}, t^{c}, \phi=0\right)=\bar{M}$
No Cooperation

Weak Trigger

Strong Trigger

Proof: Proof by contradiction: assume that $t^{c}$ is such that $M\left(\tau^{c}, t^{c}, \phi=\right.$ $0)<\bar{M}$. Then punishment next period is triggered with probability one and thus each country will play Nash policies (i.e., $t^{c}=t^{D}$ ). Next, assume that $t^{c}$ is such that $M\left(\tau^{c}, t^{c}, \phi=\theta\right)>\bar{M}$. Then either country can make a small deviation in $t$ from this equilibrium without triggering punishment. Unless $t^{c}=t^{D}$, such a deviation will be profitable and thus $M\left(\tau^{c}, t^{c}, \phi=\theta\right)>\bar{M}$ cannot be an equilibrium. Finally, assume $t^{c}$ such that $M\left(\tau^{c}, t^{c}, \phi=0\right)>$ $\bar{M}>M\left(\tau^{c}, t^{c}, \phi=\theta\right)$. In this case, punishment is triggered with probability $\alpha$, and either country can make a small deviation in $t$ from this equilibrium without increasing the probability of punishment. Unless $t^{c}=t^{D}$, such a unilateral deviation will be profitable, and thus this cannot be an equilibrium. Q.E.D.

The above Lemma suggests that it may be possible for countries to maintain some degree of cooperation (i.e., a $t^{c}<t^{D}$ ) given the use of the import trigger strategy. We refer to one possible equilibrium path as a "Weak Trigger" since it reflects cooperative policies $\left(\tau^{c}, t^{c}\right)$ and a trigger level $(\bar{M})$ such that punishment is never triggered if both countries cooperate. We refer to another possible equilibrium path as a "Strong Trigger" since it reflects 
cooperative policies $\left(\tau^{c}, t^{c}\right)$ and a trigger level $(\bar{M})$ such that punishment is randomly triggered on the realization of the low import volume shock. In the following sections, we investigate the degree of cooperation that can be maintained given each of these possible trigger strategies.

\subsection{Weak Trigger Strategies}

In this section, we take the case where the cooperative policies $\left(\tau^{c}, t^{c}\right)$ and trigger level $(\bar{M})$ are such that punishment is never triggered if both countries cooperate. However, note that this is a weak trigger since it will allow deviations from cooperative policies to (possibly) go unpunished since sufficiently small deviations from $t^{c}$ will not lower import volume sufficiently to trigger punishment in the event of a high import volume shock. Thus, small deviations from $t^{c}$ will only trigger punishment with probability $\alpha$.

Each country will set trade policy and domestic policy in each period to maximize the expected value of lifetime utility subject to the constraint that when import volume falls below $\bar{M}$ the punishment phase is triggered. In addition, since trade policy is observable, any deviation in trade policy triggers automatic punishment. Given weak triggers, setting $\tau=\tau^{c}$ and $t=t^{c}$ never triggers punishment, and thus the expected, discounted value of cooperation is given by (18). Note that a large deviation from the cooperative equilibrium in domestic policy (such that $M(\tau, t, \phi=0) \leq \bar{M}$ ) or any deviation in trade policy will trigger punishment with probability one. If a country were to make such a deviation, it would deviate to the unilaterally optimal Nash policies $\left(\tau^{N}, t^{N}\right)$. Thus, for $\tau^{c}, t^{c}$ to be self-enforcing requires that the discounted value of cooperation is greater than the discounted value of a Nash deviation:

$$
V^{C}\left(\tau^{c}, t^{c}\right) \geq W\left(\tau=\tau^{N}, \tau^{*}=\tau^{c}, t=t^{N}, t^{*}=t^{c}\right)+\delta V^{P}
$$

where $V^{P}$ represents the expected, discounted value of triggering the punishment phase. Alternatively, a small deviation from the cooperative policy (i.e., setting $t$ such that $M\left(\tau^{c}, t, \phi=0\right) \geq \bar{M}>M\left(\tau^{c}, t, \phi=\theta\right)$ will only trigger punishment with probability $\alpha$. Thus, with weak trigger strategies, small deviations will only trigger retaliation on the realization of the low import volume shock. In this case, since unilateral welfare is monotonically increasing in $t$ for $t<t^{D}$, the home country will choose the largest $t<t^{D}$ such that $M\left(\tau^{c}, t, \phi=0\right)=\bar{M}$. We refer to this optimal deviating policy as $\bar{t}^{D} .8$ Thus, the expected, discounted value of a small

\footnotetext{
${ }^{8}$ This implies that that $\bar{t}^{D}=t^{c}+2 \theta$.
} 
deviation ( $\operatorname{setting} \bar{t}^{D}$ ) is given by:

$$
V^{D}=W\left(\tau=\tau^{*}=\tau^{c}, t=\bar{t}^{D}, t^{*}=t^{c}\right)+\alpha \delta V^{P}+(1-\alpha) \delta V^{D}\left(t^{c}\right)
$$

This implies that for $\tau^{c}$ and $t^{c}$ to be self-enforcing also requires that the discounted value of cooperation is greater than the discounted value of a small (hidden) deviation in domestic policy:

$$
V^{C}\left(\tau^{c}, t^{c}\right) \geq \frac{1}{1-\delta+\alpha \delta} W\left(\tau=\tau^{*}=\tau^{c}, t=\bar{t}^{D}, t^{*}=t^{c}\right)+\frac{\alpha \delta}{1-\delta+\alpha \delta} V^{P}
$$

It should be apparent that, if $\alpha$ is sufficiently small (i.e., the probability that a small deviation will trigger punishment is small), than (35) will bind. Thus, note that while the binding enforcement constraint for an agreement covering trade and domestic policy under conditions of perfect information and certainty is given by (33), the binding constraint under conditions of imperfect information and uncertainty is potentially given by (35). As we show in the following subsections, this fact has important implications for the design of the agreement.

\subsubsection{Differential Treatment}

In this section, we consider the case where countries jointly choose $\tau^{c}$ and $t^{c}$ subject to the constraint that (35) is satisfied (i.e., neither country has an incentive to make a small (hidden) deviation in domestic policy from the agreed on policies). Our first result is that the "differential treatment" result of Ederington (2001) no longer applies in a world of imperfect information and uncertainty:

PROPOSITION 1 Within a self-enforcing international agreement with unobservable domestic policy, the most-cooperative domestic policy is distortionary (i.e., $\hat{t}^{c} \neq 0$ ).

Proof:

Assume that $\delta$ is sufficiently high and $\alpha$ is sufficiently low so that (35) binds. Taking the Lagrangian of the maximization with respect to $t^{c}$ and $\tau^{c}$ and following the calculations in the proof to Lemma 1, one derives the following condition:

$$
\frac{\partial W^{C} / \partial \tau^{c}}{\partial W^{C} / \partial t^{c}}=\frac{\partial W_{t}^{D}\left(\left(\tau=\tau^{*}=\tau^{c}, t=\bar{t}^{D}, t^{*}=t^{c}\right) / \partial \tau^{c}\right.}{\partial W_{t}^{D}\left(\tau=\tau^{*}=\tau^{c}, t=\bar{t}^{D}, t^{*}=t^{c}\right) / \partial t^{c}}
$$


Taking derivatives of the cooperative and deviating levels of welfare with respect to cooperative trade and domestic policies (and substituting in for $\bar{t}^{D}$ ) one derives that:

$$
\frac{-2 t^{c}-6 \tau^{c}}{-3 t^{c}-2 \tau^{c}}=\frac{-14 t^{c}-40 \phi-42 \tau^{c}}{-21 t^{c}-46 \phi-14 \tau^{c}}
$$

Thus, by (37), (36) is satisfied if $t^{c}=7 \tau^{c}$. Note that this implies that $t^{c}=0$ only if $\tau^{c}=0$ (i.e., only if globally efficient policies are self-enforcing). Thus, if the self-enforcement constraint binds, then both $\hat{\tau}^{c} \neq 0$ and $\hat{t}^{c} \neq 0$. Q.E.D.

The intuition behind this result is direct. The hidden aspect of domestic policy makes it more attractive as a means of deviating from an international agreement (since one can distort one's private domestic policy to restrict trade without necessarily triggering foreign punishment). When domestic policy is more likely to be used as a means of cheating on the agreement, an efficient agreement will not require full cooperation in domestic policy. Rather, cooperation in domestic policy will be relaxed so as to ensure that the agreement is self-enforcing. This result is in direct contrast to the case where domestic policy is perfectly observable, in which case any efficient self-enforcing agreement will require non-distortionary domestic policy.

\subsubsection{National Sovereignty}

Once again, consider the case where countries jointly choose $\tau^{c}$ and $t^{c}$ subject to the constraint that (35) is satisfied (i.e., neither country has an incentive to make a small (hidden) deviation in domestic policy from the agreed on policies). Our second result is that the "national sovereignty" argument of Bagwell and Staiger (2001) no longer applies in a world of uncertainty and imperfect information. Specifically, maximal cooperation can no longer be achieved simply by specifying a minimum level of market access. Rather, an efficient agreement must specify not only a level of market access (i.e., the import volume trigger, $\bar{M}$ ), but also a binding tariff ceiling (i.e., $\bar{\tau}$ ). This result is established in the following Proposition:

PROPOSITION 2 Within a self-enforcing international agreement with unobservable domestic policy, the most-cooperative equilibrium cannot be obtained by an agreement that solely establishes a minimum level of market access (i.e., an import volume trigger). Rather, such an agreement must also establish a binding tariff ceiling. 
Proof:

Assume that $\delta$ is sufficiently high and $\alpha$ is sufficiently low so that (35) binds. First, assume an agreement that specifies both a binding tariff ceiling $(\bar{\tau})$ and minimum level of market access $(\bar{M})$ such that either $\tau>\bar{\tau}$ or $M(\tau, t, \phi)<$ $\bar{M}$ will trigger Nash reversion. In this case, the self-enforcement constraints are given by (33) and (35).

Next, assume an agreement that specifies only an import volume trigger and not an additional binding tariff ceiling. In this case, small deviations in either trade policy or domestic policy (such that $M(\tau, t, \phi=0) \geq \bar{M}>$ $M(\tau, t, \phi=\theta)$ ) will only trigger punishment with probability $\alpha$. Thus, in addition to (33) and (35), there is an additional constraint that no country has an incentive to make a small deviation in trade policy. Refer to this deviating trade policy as $\bar{\tau}^{D}$ (i.e., a $\tau$ such that $M\left(\tau, t^{c}, \phi=0\right)=\bar{M}$ ). The self-enforcement constraint with respect to such a deviation is given by:

$V^{C}\left(\tau^{c}, t^{c}\right) \geq \frac{1}{1-\delta+\alpha \delta} W\left(\tau=\bar{\tau}^{D}, \tau^{*}=\tau^{c}, t=t^{c}, t^{*}=t^{c}\right)+\frac{\alpha \delta}{1-\delta+\alpha \delta} V^{P}$

Given the definitions of $\bar{t}^{D}$ and $\bar{\tau}^{D}$ it is direct to derive (since domestic policy is an inefficient means of restricting market access) that, for any given $\bar{M}$ :

$$
W\left(\tau=\bar{\tau}^{D}, \tau^{*}=\tau^{c}, t=t^{c}, t^{*}=t^{c}\right)>W\left(\tau=\tau^{*}=\tau^{c}, t=\bar{t}^{D}, t^{*}=t^{c}\right)
$$

This implies that (38) is a more binding constraint than (35). Thus, an agreement that specifies both an import volume trigger $(\bar{M})$ and a binding tariff ceiling $(\bar{\tau})$ can support a greater degree of cooperation (i.e., a greater $V^{C}$ ) than an agreement that just sets the import volume trigger. Q.E.D.

As is shown in the proof to the above proposition, an efficient agreement will specify both a minimum level of market access $(\bar{M})$ and a binding tariff ceiling $(\bar{\tau})$. Thus countries, by sacrificing some sovereignty in setting policy, can achieve greater cooperation in an international agreement. The key to this result lies in the constraints that enforcement places on sustained cooperation. In a world of uncertainty and imperfect information, countries have an incentive to make small deviations from any implicit agreement in the hope that such deviations will not trigger retaliation. If the agreement only specifies a level of market access, than countries can pursue such terms-oftrade deviations with trade policy. Thus, by binding the observable policy 
$\left(\tau^{c}\right)$ any country would be forced to use less-efficient domestic policy as a means of deviating. Being forced to use a less-efficient policy reduces the desire to deviate and thus allows greater cooperation to be maintained. What is noteworthy about this result is, as is pointed out by Bagwell and Staiger (2001), this can be interpreted as exactly what the articles of GATT require. Specifically, tariff commitments are established by negotiated bound tariffs, while market access commitments are established by the non-violation complaints of Article XXIII.

In a situation of perfect information and certainty Bagwell and Staiger (2001) argue that binding a countries tariffs can impede the attainment of globally efficient outcomes by deterring countries from making changes to their domestic policies that would increase access to their markets. Thus, Bagwell and Staiger (2001) argue for providing greater sovereignty to countries in choosing their policy mix than is currently provided under GATT rules. Basically, they argue that countries should be allowed to raise tariffs above bound levels without triggering punishment (provided they maintain the specified level of imports). In contrast, we argue that current GATT restrictions on trade policy (i.e., bound tariffs) can be justified as a means of enforcing greater cooperation in a world of uncertainty about a country's domestic policies. Intuitively, this is because domestic policy is only a second-best means of restricting market access. Thus, since binding tariffs force countries to use less efficient domestic policy as a means of cheating on the agreement, it also reduces the incentives countries have to deviate from the agreement.

\subsubsection{Linkage}

Finally, we consider the potential benefits of linkage (i.e., allowing crossretaliation over trade and domestic policy) with weak trigger strategies. As before assume that parameter values are such that (35) is the binding constraint (i.e., $\tau^{c}$ and $t^{c}$ are such that neither country has an incentive to make a small (hidden) deviation in domestic policy from the agreed on policies). One might expect the stronger punishment of linkage to be weakly preferred in an agreement with weak trigger strategies since, even in the presence of unobservable domestic policy, the punishment phase is never triggered. As we show in the following proposition, this is exactly the case:

PROPOSITION 3 Within a self-enforcing international agreement with unobservable domestic policy but weak trigger strategies, allowing crossretaliation across policy instruments is weakly optimal (i.e., a linked agree- 
ment is weakly preferred to a non-linked agreement).

Proof:

As before, consider the case where (35) binds. In a linked agreement, such a small deviation in domestic policy will trigger reversion to the Nash equilibrium in both policies (such that $V^{P}=\frac{1}{1-\delta} W^{N}$ ). In contrast, in a non-linked agreement the identical deviation in domestic policy will only trigger reversion to the Nash equilibrium in domestic policy (such that $V^{P}=\frac{1}{1-\delta} W_{t}^{N}$ ). The fact that linkage is weakly optimal simply follows from the fact that punishment through reversion to the Nash equilibrium in both policies is greater than punishment in a single policy instrument $\left(W_{t}^{N} \geq W^{N}\right)$ and thus linkage relaxes the constraint (35).

However, in contrast to the perfect certainty case, the assumption of unobservable domestic policy increases the incentive to deviate in domestic policy alone, and thus breaks the equivalence between linked and non-linked agreements:

PROPOSITION 4 Within a self-enforcing agreement with unobservable domestic policy, a linked may be strictly preferred to a non-linked agreement, even in the absence of cross-border (non-pecuniary) externalities.

Proof:

As before, consider the case where (35) binds. In a linked agreement, a small deviation in domestic policy will trigger reversion to $\left.W^{N}\right)$. Thus, from (35) one can derive that globally efficient policies (i.e., $\hat{\tau}^{c}=0$ and $\hat{t}^{c}=0$ ) are self-enforcing provided that:

$$
\delta \geq \frac{800 \theta(1-4 \alpha \theta-23 \theta)}{21 \alpha+8 \theta\left[100-21 \alpha^{2}-2300 \theta-400 \alpha \theta+42 \alpha^{3} \theta\right]}
$$

In contrast, in a non-linked agreement, a small deviation in domestic policy will trigger reversion to $\left.W_{t}^{N}\right)$. Thus, from (35) one can derive that globally efficient policies (i.e., $\hat{\tau}^{c}=0$ and $\hat{t}^{c}=0$ ) are self-enforcing provided that:

$$
\delta \geq \frac{2116 \theta(1-4 \alpha \theta-23 \theta)}{21 \alpha+4 \theta\left[529-42 \alpha^{2}-12167 \theta-2116 \alpha \theta+84 \alpha^{3} \theta\right]}
$$

Thus, provided that $\alpha$ is sufficiently small (i.e., the probability of a deviation triggering punishment is sufficiently low), the set of $\delta$ which support globally efficient policies is larger for the linked agreement. Thus, there exists 
parameter values for which the linked agreement can support greater degree of cooperation. Q.E.D.

Intuitively, although linkage and non-linkage are equivalent with perfect information, the non-transparency of domestic policy makes it a more attractive instrument with which to deviate. Thus, while the self-enforcement constraints for single policy deviations are non-binding in a world of perfect certainty (thus, resulting in the equivalence of linked and non-linked agreements), they can bind in a world of imperfect information. Such a result is ironic in a sense as many trade economists are skeptical about the wisdom of allowing cross-retaliation, fearing that the use of trade policy sanctions as a means of enforcing cooperation over a host of issues might undermine the advances that have been achieved in reducing trade barriers. Specifically, they fear that allowing cross-retaliation could result in disputes covering domestic policy to spillover into the trade arena. Such concerns are moot in a world of perfect information as trade disputes never actually occur in equilibrium (and linkage and non-linkage are functionally equivalent). However, the above proposition suggests that the presence of uncertainty and imperfect information, far from making cross-retaliation undesirable, could actually strengthen the case for policy linkage.

\section{$5 \quad$ Strong Triggers}

In this section, we consider the case where the cooperative policies $\left(\tau^{c}, t^{c}\right)$ and trigger level $(\bar{M})$ are such that punishment is randomly triggered with probability $\alpha$ even if countries cooperate. However, note that this is a strong trigger since any attempt to deviate from cooperative policies (in either trade or domestic policy) by reducing market access will trigger punishment with probability one.

Each country will set domestic policy in each period to maximize the expected value of lifetime utility subject to the constraint that when import volume falls below $\bar{M}$ the punishment phase is triggered. Note that with a strong trigger, even if the home country were to set $\tau=\tau^{c}$ and $t=t^{c}$, punishment is triggered with probability $\alpha$. Thus, the expected, discounted value of cooperation is given by:

$$
V^{C}\left(\tau^{c}, t^{c}\right)=W\left(\tau^{c}, t^{c}\right)+\alpha \delta V^{P}+(1-\alpha) \delta V^{C}\left(t a u^{c}, t^{c}\right)
$$

Since, if the home country were to deviate from the agreement, it would deviate to unilaterally optimal policies $\left(\tau^{N}\right.$ and $\left.t^{N}\right)$, the expected discounted value of deviating and triggering automatic punishment is given by: 


$$
D_{\tau, t} \equiv W\left(\tau=\tau^{N}, t=t^{N}, \tau^{*}=\tau^{c}, t^{*}=t^{c}\right)+\delta V^{P}
$$

It is direct to derive from (42) and (43) that $\tau=\tau^{*}=\tau^{c}, t=t^{*}=t^{c}$ can be supported as a self-enforcing equilibrium (i.e., $V^{C} \geq D_{\tau, t}$ ) if:

$W\left(\tau^{c}, t^{c}\right) \geq(1-\delta+\alpha \delta) W\left(\tau=\tau^{N}, \tau^{*}=\tau^{c}, t=t^{N}, t^{*}=t^{c}\right)+\delta(1-\alpha)(1-\delta) V^{P}$

First, note from (44), that an increase in $\alpha$ reduces the degree of cooperation that can be maintained. Intuitively, this is due to the fact that if $\alpha$ is high, then cooperation is likely to be randomly abandoned and thus deviation is profitable. Second, note that with a strong trigger agreement, this is the only self-enforcement constraint that must be satisfied. Thus, the situation of strong triggers is similar to the perfect certainty case of Section 3 in that any deviation triggers automatic punishment, and thus countries that choose to cheat will deviate to the Nash equilibrium. Given this similarity, one might expect the results of Ederington (2001) and Bagwell and Staiger (2001) to once again apply. As we show in the following propositions, this is indeed the case:

PROPOSITION 5 Within a self-enforcing international agreement with strong trigger strategies, the most-cooperative domestic policy is non-distortionary (i.e., $\left.\hat{t}^{c}=0\right)$.

Proof:

The proof follows that of Lemma 1.

PROPOSITION 6 Within a self-enforcing international agreement with strong trigger strategies, the most-cooperative equilibrium can be obtained by an agreement that simply establishes a minimum level of market access (i.e., an import volume level) that each country must maintain.

Proof:

The proof follows that of Lemma 2

However, the main difference between a self-enforcing agreement with perfect certainty and a self-enforcing agreement with strong trigger strategies is the addition of a random probability $(\alpha)$ that reversion to the punishment phase will be triggered. The question this raises is whether a non-linked agreement would be preferable as a means of reducing the loss to randomly generated punishment. 
As in the linked agreement, the expected, discounted value of cooperation in a non-linked agreement is given by (42). However, in a linked agreement any deviation (such that either tariffs are above their binding levels or import volume is below its binding level) triggers reversion to the full Nash equilibrium and thus $V^{P}=\frac{1}{1-\delta} W^{N}$. In contrast, in a non-linked agreement a deviation in solely domestic policy (so that the import volume falls below it's binding level, but tariffs remain at cooperative levels) triggers reversion to the Nash equilibrium in domestic policy alone (i.e., only the agreement covering domestic policy is abandoned). Thus, in the non-linked agreement $\left.V^{P}=\frac{1}{1-\delta} W_{t}^{N}\right)$. Since reversion to the full Nash equilibrium is more severe (i.e., $W_{t}^{N} \geq W^{N}$ for $\hat{\tau}^{c}, \hat{t}^{c}$ ), the discounted value of cooperating in a non-linked agreement is actually higher than the discounted value of cooperating in a linked agreement (i.e., $\left.V^{N L}\left(\tau^{c}, t^{c}\right)>V^{L}\left(\tau^{c}, t^{c}\right)\right)$. These calculations offer a potential explanation for why, in the presence of uncertainty, a linked agreement covering multiple policy instruments may be suboptimal. Of course the benefit of the stronger punishment of linkage is that it typically allows for a greater degree of cooperation to be maintained (i.e., it allows lower $\tau^{c}$ and $t^{c}$ to be supported as a self-enforcing equilibrium). However, as we show in the Proposition below, the increased punishment of policy linkage is unnecessary, and thus non-linkage is strictly preferred:

PROPOSITION 7 Within a self-enforcing international agreement with unobservable domestic policy but strong trigger strategies, forbidding crossretaliation across policy instruments is optimal (i.e., a non-linked agreement is strictly preferred to a linked agreement).

Proof:

Define $V^{N L}\left(V^{L}\right)$ as the discounted value of cooperation in a non-linked (linked) agreement. Define $D_{\tau, t}^{N L}\left(D_{\tau, t}^{L}\right)$ as the discounted value of deviating in both policies from a non-linked (linked) agreement. $V^{N L}$ is given by (42) where $V^{P}=\frac{1}{1-\delta} W_{t}^{N}$. If a country deviates in both policies, such that $\tau>\tau^{c}$ and $M(\tau, t, \phi)<\bar{M}$, this triggers reversion to the full Nash equilibrium. The expected value of such a deviation is given by (43) where $V^{P}=\frac{1}{1-\delta} W^{N}$. Thus, for a given $\tau^{c}$ and $t^{c}, V^{N L}>V^{L}$ and $D_{\tau, t}^{N L}=D_{\tau, t}^{L}$, and the selfenforcement constraint for multiple policy deviations is less binding in the non-linked agreement.

Alternatively, a country could deviate in solely domestic policy, such that $\tau=\tau^{c}$ and $M\left(\tau^{c}, t, \phi\right)<\bar{M}$, thus triggering reversion to the Nash equilibrium in domestic policy alone. The expected value of such a deviation 
is given by:

$$
D_{t}^{N L} \equiv W\left(\tau=\tau^{c}, t=t^{D}\left(\tau^{c}\right), \tau^{*}=\tau^{c}, t^{*}=t^{c}\right)+\frac{\delta}{1-\delta} W_{t}^{N}
$$

Evaluated at most-cooperative policies for the linked agreement (i.e., $\hat{\tau}^{c}, \hat{t}^{c}=$ 0 such that $V^{L}=D_{\tau, t}^{L}$ ), it is direct to derive that the self-enforcement constraint for deviation in domestic policy from the non-lined agreement does not bind (i.e., $V^{N L}>D_{t}^{N L}$ provided that:

$$
\frac{W\left(\tau=\tau^{N}, \tau^{*}=\tau^{c}, t=t^{N}, t^{*}=t^{c}\right)-W\left(\tau^{c}, t^{c}\right)}{W\left(\tau=\tau^{c}, t=t^{D}\left(\tau^{c}\right), \tau^{*}=\tau^{c}, t^{*}=t^{c}\right)-W\left(\tau^{c}, t^{c}\right)}=\frac{W\left(\tau^{c}, t^{c}\right)-W^{N}}{W\left(\tau^{c}, t^{c}\right)-W_{t}^{N}}
$$

Substituting in for the respective welfare functions and evaluating at most-cooperative policies, $\hat{\tau}^{c}, \hat{t}^{c}=0$, one finds the above condition is satisfied if:

$$
\frac{3\left(-1+4 \alpha \theta+20 \hat{\tau}^{c}\right)^{4}}{20736800}>0
$$

Thus, one finds that the above condition is indeed satisfied. ${ }^{9}$ Thus, the self-enforcement constraint for a single issue deviation is also less binding in the non-linked agreement. Since none of the enforcement constraints for the non-linked agreement bind (at the point where $V^{L}=D_{\tau, t}^{L}$ ), the non-linked agreement is strictly preferred since $V^{N L}>V^{L}$ for any given $\tau^{c}, t^{c}$ policy pair. Q.E.D.

A common criticism of linkage is that conflicts with respect to the domestic policy portion of the agreement (e.g., disputes of environmental regulations) may undermine international trade agreements. As we have shown, such concerns can be formalized by a model in which domestic policy is unobservable. Any agreement covering unobservable policies must rely on some type of trigger strategy to induce cooperation. However, given random, unobservable shocks, such agreements carry the risk that punishment will be periodically triggered even when no deviation has taken place. ${ }^{10}$ Therefore, countries will be concerned with minimizing the losses to reverting to

\footnotetext{
${ }^{9}$ This is similar to the proof, in Lemma 4 that self-enforcement with respect to domestic policy deviations is a slack constraint in the non-linked agreement with perfect information. Intuitively, since domestic policy is a less efficient means of restricting market access, countries have less incentive to deviate in domestic policy.

${ }^{10}$ It should be noted that carrying out such punishment is not a "mistake", but is necessary to make the punishment threat credible and thus deter deviations.
} 
the punishment phase. What we argue in the above proposition is that using trade policy sanctions to punish deviations from the import volume trigger is unnecessarily severe punishment (i.e., it is not necessary to deter deviations in domestic policy). Thus, delinking trade and domestic policy agreements, which minimizes the losses from random punishment episodes, will be strictly preferred.

\section{Conclusion}

A key question in recent trade negotiations is how to integrate domestic polices (such as environmental regulations and labor standards) into conventional trade agreements. In this paper, we consider the efficient design of such an international trade agreement when trade policy is observable but domestic policy is unobservable. We consider this a relevant situation since, while trade barriers might be readily apparent to foreign countries, the actual enforcement of many purely domestic regulations is not. The basic conclusion of this paper is that the observability of domestic policy is crucial as many of the main rules that govern the efficient treatment of domestic policy in a world of perfect information do not extend to a situation of asymmetric information.

\section{Reference}

Abreu, D. (1988). On the Theory of Infinitely Repeated Games with Discounting. Econometrica, 56, 383-396.

Bagwell, K. and Staiger, R. (1990). A Theory of Managed Trade. American Economic Review, 80, 779-795.

Bagwell, K. and Staiger, R. (1999). An Economic Theory of GATT. American Economic Review, 89, 215-248.

Bagwell, K. and Staiger, R. (2001). Domestic Policies, National Sovereignty and International Economic Institutions. The Quarterly Journal of Economics, 116, 519-562.

Copeland, B. (1990). Strategic Interaction among Nations: Negotiable and Non-Negotiable Trade Barriers. Canadian Journal of Economics, 23, 64-108. 
Dixit, A. (1987). Strategic Aspects of Trade Policy. In T.Bewley (Ed.), Advances in Economic Theory: Fifth World Congress. Cambridge University Press.

Ederington, J. (2001). International Coordination of Trade and Domestic Policies. American Economic Review, 91, 1580-1593.

Ederington, J. (2002). Trade and Domestic Policy Linkage in International Agreements. International Economic Review, 43, 1347-1367.

Green, E. and Porter, R. (1984). Noncooperative Collusion Under Imperfect Price Information. Econometrica, 52, 87-100.

Hungerford, T. (1991). GATT : A Cooperative Equilibrium in a Noncooperative Trading Regime. Journal of International Economics, 31, $357-369$.

Limao, N. (2005). Trade Policy, Cross-Border Externalities and Lobbies: Do Linked Agreements Enforce More Cooperative Outcomes?. Journal of International Economics, 67, 175-199.

Riezman, R. (1991). Dynamic Tariffs with Asymmetric Information. Journal of International Economics, 30, 267-283.

Spagnolo, G. (1996). Issue Linkage, Delegation and International Policy Cooperation. Tech. rep. 49.96, Fondazione Eni Enrico Mattei. 